\title{
Incidental Finding of an Elongated Styloid Process during Tonsillectomy Procedure
}

\author{
Loay Al-Ekri, Abdulkarim Alsaei \\ Department of ENT, Head \& Neck Surgery, Salmaniya Medical Complex, Manama, Kingdom of Bahrain \\ Email: loayalekri@gmail.com, asaie@health.gov.bh
}

Received 7 March 2015; accepted 15 May 2015; published 18 May 2015

Copyright (C) 2015 by authors and Scientific Research Publishing Inc.

This work is licensed under the Creative Commons Attribution International License (CC BY). http://creativecommons.org/licenses/by/4.0/

(c) (i) Open Access

\begin{abstract}
Patients with recurrent throat pain, dysphagia, or facial pain symptoms might have Eagle's syndrome due to abnormal length of the styloid process or calcification of stylohyoid ligament complex. In adults, the styloid process is approximately $2.5 \mathrm{~cm}$ long. The etiology of this disease is not well understood, and usually asymptomatic. In some cases, the styloid tip, which is located between the external and internal carotid arteries, compresses the perivascular sympathetic fibers, resulting in a persistent pain. The disease can be diagnosed by physical examination through digital palpation of the styloid process in the tonsillar fossa or by radiographic workup that includes anterior-posterior and lateral skull films. We report a 33-year-old woman with an incidental finding of an elongated styloid process during a routine tonsillectomy procedure.
\end{abstract}

Keywords

Elongated Styloid Process, Eagle's Syndrome

\section{Introduction}

Styloid process (Processus styloideus) of the temporal bone is a cylindrical bony projection attached to base of the skull and situated immediately anterior to the stylomastoid foramen. It extends downwards, forwards and slightly medially. From its extremity, the stylohyoid ligament passes downwards and forwards to the lesser horns of the hyoid bone. The process is covered laterally by the parotid gland, and the facial nerve crosses its base, while the tip is situated between the internal and external carotid arteries, laterally from the pharyngeal wall and immediately behind the tonsil fossa. The anterior surface of the styloid gives origin to styloglossus muscle and its tip to stylohyoid muscle. On its deep surface, the process is separated from internal jugular vein by the origin of stylopharyngeus muscle [1].

Styloid process is derived from the second branchial arch of Reichert's cartilage and is part of the stylohyoid

How to cite this paper: Al-Ekri, L. and Alsaei, A. (2015) Incidental Finding of an Elongated Styloid Process during Tonsillectomy Procedure. International Journal of Otolaryngology and Head \& Neck Surgery, 4, 236-240.

http://dx.doi.org/10.4236/ijohns.2015.43040 
complex along with the lesser horns of hyoid bone and stylohyoid ligament. In adults, the styloid process is normally composed of dense connective tissue, but may retain its embryonic cartilage and the potential for ossification [2].

The length of the styloid process is usually $2-3 \mathrm{~cm}$. When it is more than $3 \mathrm{~cm}$, it is called as an elongated styloid process. This elongation was first described in 1937 by Eagle who defined "stylalgia" as pain associated with abnormal length of the styloid process and later called the Eagle's syndrome [3].

Elongation of the process may cause various clinical symptoms as neck and cervico-facial pain. Patients most often complain of pain, a sensation of foreign body or fish bone in the pharynx, and odynophagia. Clinically, hardness can occasionally be felt in the tonsillar fossa which is painful on palpation. If the styloid process causes pressure on the area of the carotid arteries, the symptoms are more complicated. The patient may record buzzing in the ears, headache around the orbit, or pain during head movement. [4]

The incidence of the elongated styloid process was determined around $4 \%-7 \%$, and revealed a female dominance. Out of these people, only $4 \%-10 \%$ of them are symptomatic. The mean length of the styloid processes of the subjects reporting Eagle's syndrome was about $40 \mathrm{~mm} \mathrm{[5].} \mathrm{Some} \mathrm{reports} \mathrm{have} \mathrm{described} \mathrm{that} \mathrm{it} \mathrm{is}$ the abnormal anterior angulation rather than elongation that is responsible for the symptoms [6].

\section{Case Report}

A 33-year-old Bahraini lady with a chronic history of recurrent attacks of tonsillo-pharyngitis and a persistent sensation of sore throat and odynophagia of more than 2 years' duration. There was no history of localized facial or neck pain, or foreign body sensation. She was booked for a routine tonsillectomy procedure. After a complete removal of both tonsils by cold dissection method and control of bleeding by electro cautery, an elongated apparent styloid process was noticed in the bed of the right tonsillar fossa, while the left side showed a slight bulge behind the superior constrictor muscle (Figure 1).

The patient was doing fine post operatively on intravenous hydration and medication and well tolerating her post tonsillectomy pain. She was kept in hospital for 3 days with no record of bleeding. About a week after the surgery, a regular follow up visit to ENT clinic showed an almost complete healing of both tonsillar fossae, with the apparent styloid process hidden behind the anterior pillar of the right side. Apart from the usual post Ty pain, the patient reported some localized symptoms of throat pain on the right side of the neck 'stylalgia'. On the following weeks of a routine follow-up visit, the patient reported no further symptoms of odynophagia, or cervico-facial pain.

Looking back through the patient's history of investigations, previous plain x-ray films have confirmed the diagnosis of a unilateral right sided elongated styloid process. It showed that the right styloid process was longer and thicker, measuring about $3.3 \mathrm{~cm}$ long, while the left one measured about $2.7 \mathrm{~cm}$ long (Figure 2 and Figure 3).

\section{Discussion}

Eagle syndrome is characterized by recurrent pain in the head and neck region due to an elongated styloid process or calcified stylohyoid ligament. In his classic description, Eagle defined two clinical features caused by elongated styloid process. The classical stylohyoid syndrome which is almost invariable occurs after tonsillectomy.
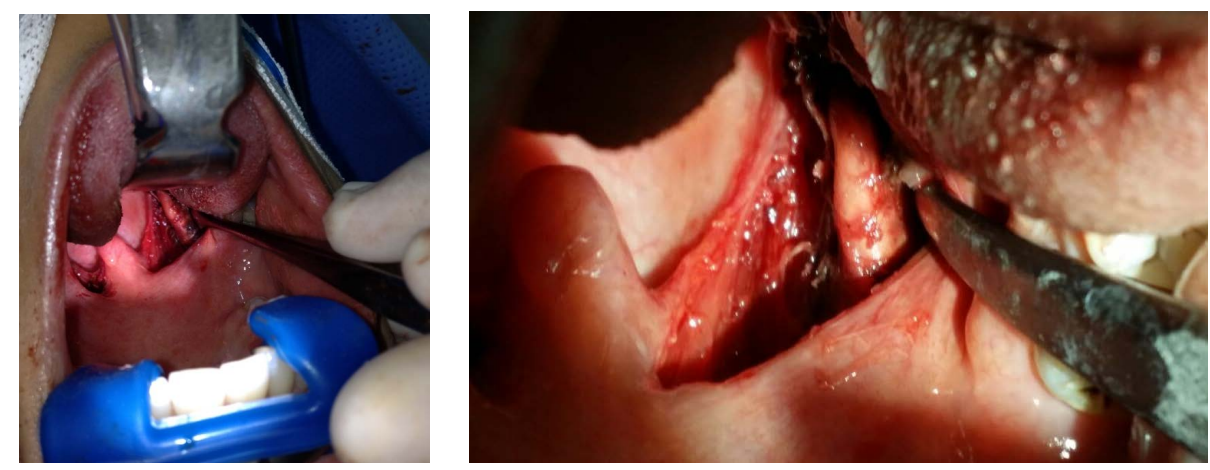

Figure 1. Intra-op pictures showing exposed elongated styloid process in the right tonsillar fossa. 


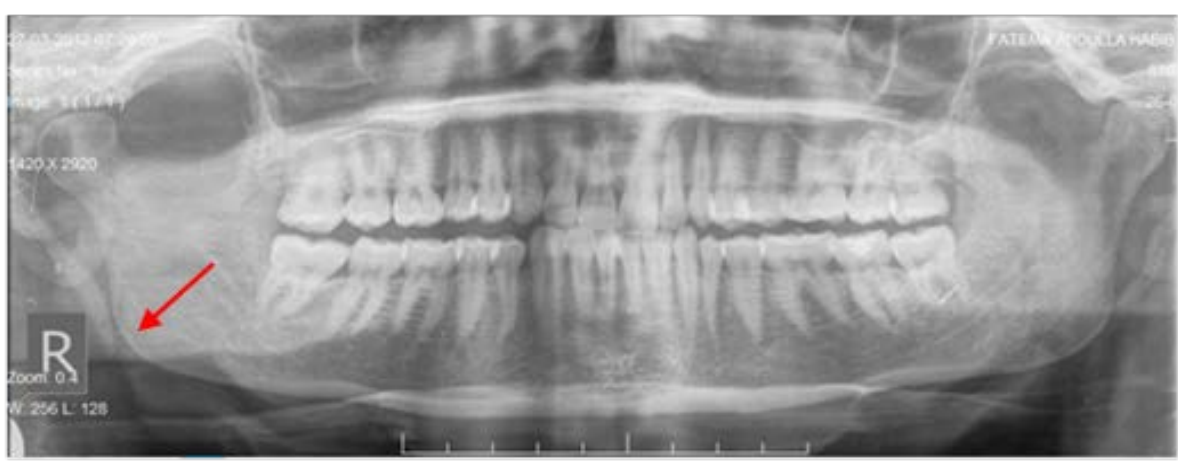

Figure 2. Orthopantomogram (OPG) showing a right-sided unilateral elongated styloid process (red arrow).

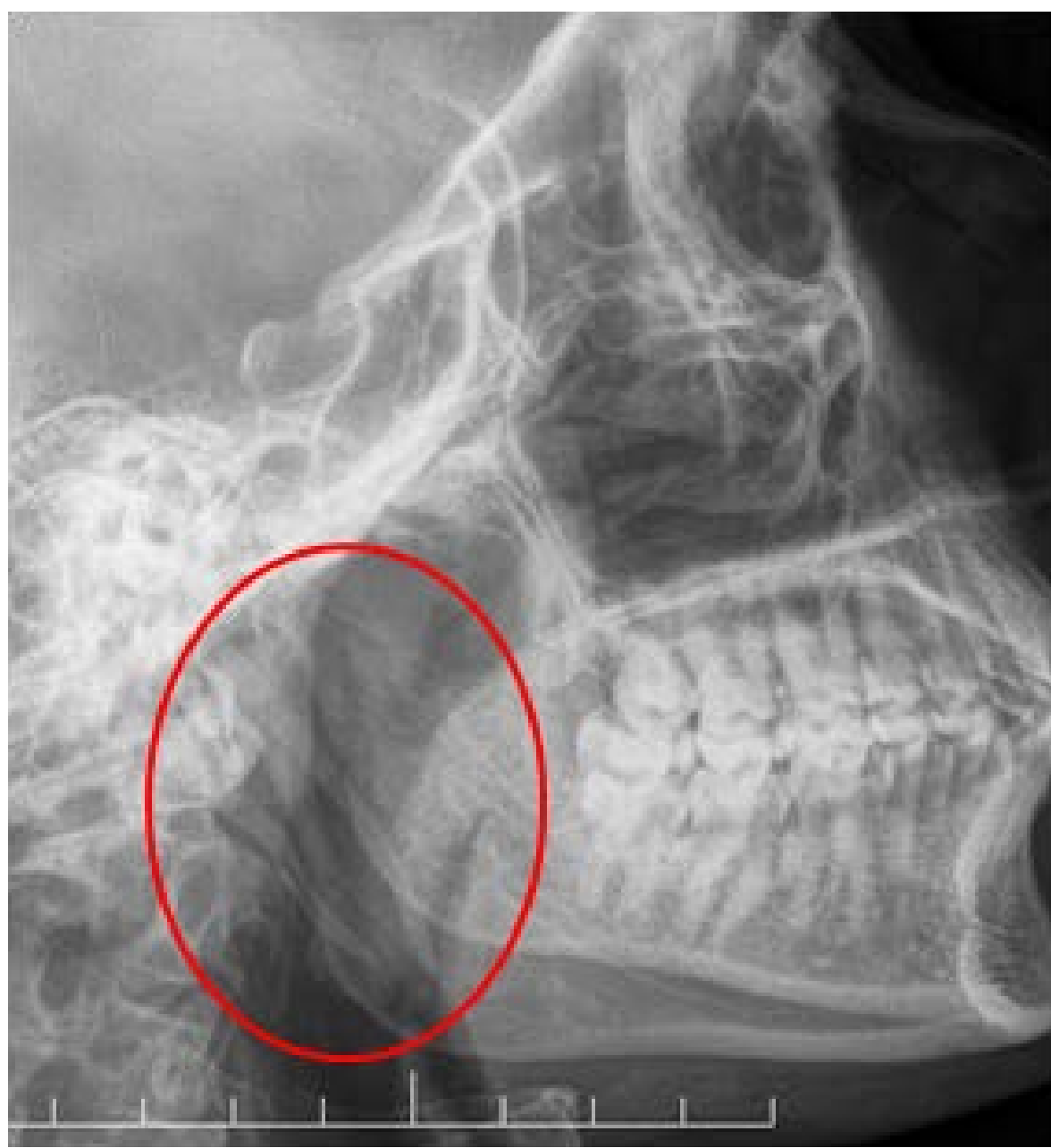

Figure 3. Lateral neck X-ray showing a unilateral elongated styloid process, the (red circle) clearly shows the difference in length between the two styloid processes.

It usually presents with a dull ache in the lateral pharyngeal wall and ipsilateral ear. This pain classically starts during the first week following tonsillectomy and remains at the same intensity level thereafter. The stylocarotid syndrome develops spontaneously, and is associated with cervical, ocular and facial pain, due to irritation of the area around the carotid artery [7] [8].

It is a rare condition and most of the patients may be asymptomatic; however, when these ossified structures 
exert pressure on the various structures in the head and neck, there can be a wide range of symptoms, including pharyngeal discomfort, painful neck movements, change in voice, painful tongue movements, increased secretion of saliva, otalgia, and headache [9].

Eagle also defined the length of a normal styloid process at $2.5-3.0 \mathrm{~cm}$. The cause of this elongation of the styloid process is not well understood. It can be idiopathic, congenital (due to the persistence of cartilaginous elements of precursors of the styloid process), or acquired (due to the proliferation of osseous tissue at the insertion of the stylohyoid ligament).

An elongated styloid process occurs in about $4 \%$ of the general population, while only small percentages (between $4 \%$ and 10\%) of these patients are symptomatic. In fact, the number of reported cases is underestimated because it is an incidental finding in radiographs. Diagnosis is supported by description of symptoms by patients, previous history of any cervical trauma and tonsillectomy, physical examination, and radiographs [10].

The symptoms have varied pathophysiological explanations, for example, symptoms may be due to: 1) fracture of the styloid process leading to granulation tissue and pressure on the surrounding structures; 2) compression of adjacent nerves, e.g., the glossopharyngeal, the lower branch of the trigeminal, or the chorda tympani; 3 ) degenerative and inflammatory changes at the tendinous portion of the stylohyoid insertion; 4) irritation of the pharyngeal mucosa due to direct compression, or post-tonsillectomy scarring involving the cranial nerves V, VII, IX, and X; 5) impingement of the carotid vessels with irritation of the sympathetic nerves in the arterial sheath [11].

Radiographs of the skull, both antero-posterior and lateral views, can reveal the elongated styloid process, but the superimposition of various other structures often makes diagnosis difficult. The development of threedimensional CT (3D CT) has made it easier to delineate the anatomy of the surrounding structures. 3D CT is of great help when surgical correction is planned [12].

Surgical resection of elongated styloid process is the primary treatment for Eagle's syndrome. Even though medical treatment using analgesic or local steroid injection is an option, the condition is not yet proven to be well treated or resolved. There are two surgical methods that have been suggested: transoral and external transcervical approaches. Transoral resection, as described by Eagle, is technically easier. The protuberance of styloid process is identified and overlying mucosa is incised. Dissection over the superior constrictor muscle is performed to expose the tip and skeletonization is done until its origin. The ligaments and muscle tendons attached to it are separated and the free process is resected using bone nibbler as near as possible to its base. Then, muscles and mucosa over the surgical bed are closed in layers. Surgical failure rate is around $20 \%$ by means of partial relief of or recurrence of symptoms and can be due to inadequate shortening leading to constant irritation [13].

In review of the literature, we did not come across a similar report of an incidental finding of elongated styloid process while performing tonsillectomy. In fact, this case had brought an interesting scientific debate and discussion in the department of otolaryngology, head and neck surgery in regards to what should have been done for this patient and others if such a finding was encountered during a routine tonsillectomy. Should the elongated styloid process be excised and removed from the bed of the tonsillar fossa at the same time, to minimize the risk of eagle syndrome? Or should we leave it untouched and follow up the patient over a period of time to observe for the development of stylalgia? It will be very interesting to hear from other people and listen to their experience in managing asymptomatic elongation of the styloid process.

\section{Conflicts of Interest}

The authors declare no conflicts of interest or funding sources.

\section{Consent to Publish}

The patient was verbally consented and agreed to write a case report about her condition and accepted to publish it for educational and scientific purposes.

\section{References}

[1] Gray, H. (1918) Anatomy of the Human Body, the Temporal Bone.

[2] Kolagi, S.I. (2010) Elongated Styloid Process—-Report of Two Rare Cases. International Journal of Anatomical Varia- 
tions, 3, 100-102.

[3] Eagle, W.W. (1937) Elongated Styloid Process: Report of Two Cases. Archives of Otolaryngology, 25, 584-587. http://dx.doi.org/10.1001/archotol.1937.00650010656008

[4] Sandev, S. and Sokler, K. (2000) Styloid Process Syndrome. ActaStomat Croat, 34, 451-456.

[5] Balcioglu, H.A., Kilic, C., Akyol, M., Ozan, H. and Folia, K.G. (2009) Length of the Styloid Process and Anatomical Implications for Eagle's Syndrome. Folia Morphologica, 68, 265-270.

[6] Yavuz, H., Caylakli, F., Yildirlm, T. and Ozluoglu, L.N. (2008) Angulation of the styloid Process in Eagle's Syndrome. European Archives of Oto-Rhino-Laryngology, 265, 1393-1396. http://dx.doi.org/10.1007/s00405-008-0686-9

[7] Eagle, W.W. (1948) Elongated Styloid Process: Further Observations and a New Syndrome. Archives of Otolaryngology, 47, 630-640. http://dx.doi.org/10.1001/archotol.1948.00690030654006

[8] Eagle, W.W. (1958) Elongated Styloid Process, Symptoms and Treatment. JAMA Otolaryngology—Head \& Neck Surgery, 67, 172-176. http://dx.doi.org/10.1001/archotol.1958.00730010178007

[9] Rechtweg, J.S. and Wax, M.K. (1998) Eagle's Syndrome: A Review. American Journal of Otolaryngology, 19, 316321. http://dx.doi.org/10.1016/S0196-0709(98)90005-9

[10] Sadaksharam, J. and Singh, K. (2012) Stylocarotid Syndrome: An Unusual Case Report. Contemporary Clinical Dentisity, 3, 503-506. http://dx.doi.org/10.4103/0976-237X.107456

[11] Murtagh, R.D., Caracciolo, J.T. and Fernandez, G. (2001) CT Findings Associated with Eagle Syndrome. American Journal of Neuroradiology, 22, 1401-1402.

[12] Raina, D., Gothi, R. and Rajan, S. (2009) Eagle Syndrome. Indian Journal of Radiology Imaging, 19, $107-108$. http://dx.doi.org/10.4103/0971-3026.50826

[13] Baharudin, A., Rohaida, I. and Khairudin, A. (2012) Transoral Surgical Resection of Bilateral Styloid Processes Elongation (Eagle's Syndrome). Acta Informatica Medica, 20, 133-135. http://dx.doi.org/10.5455/aim.2012.20.133-135 